\title{
A rare case of peritoneo-cutaneous fistula after cesarean section
}

\author{
Anshul Rana*, Neha Mohindroo \\ Department of Obstetrics and Gynecology, Indira Gandhi Medical College, Shimla, Himachal Pradesh, India
}

Received: 30 July 2020

Revised: 07 September

Accepted: 08 September 2020

\author{
*Correspondence: \\ Dr. Anshul Rana, \\ E-mail: anshulrana_10j@yahoo.co.in
}

Copyright: $\odot$ the author(s), publisher and licensee Medip Academy. This is an open-access article distributed under the terms of the Creative Commons Attribution Non-Commercial License, which permits unrestricted non-commercial use, distribution, and reproduction in any medium, provided the original work is properly cited.

\begin{abstract}
Peritoneo-cutaneous fistula is usually a rare but known entity. Such a case has not been reported after cesarean sections. A 26-year female presented to our clinic in May 2019 with persistent sero-purulent discharge from sinus over abdominal skin. The patient had previously undergone a cesarean section in April 2018 for premature rupture of membranes and non-progress of labour. The surgery and puerperal period were uneventful. The patient presented with document highgrade fever in June 2018. In August 2018, a localized painful swelling was noted by the patient herself over the abdomen, contrast-enhanced computed tomography, which suggested $6.3 \times 3.9 \times 3 \mathrm{~cm}$ collection in the right adnexal region and a fistulous tract communicating with abdominal skin. For the same she underwent surgery, wide local excision of the fistulous tract around elliptical skin incision was done. The development of delayed peritoneo-cutaneous fistula has been seen as a complication of difficult cholecystectomy.
\end{abstract}

Keywords: Peritoneo-cutaneous fistula, Fistula, Cesarean section complications

\section{INTRODUCTION}

Peritoneo-cutaneous fistula is usually a rare but known entity. It is usually seen in patients with either leftover stone in the abdominal cavity after cholecystectomy or following other percutaneous interventions. ${ }^{1,2}$ This case report presents a rare case of peritoneo-cutaneous fistula post-cesarean section.

\section{CASE REPORT}

A 26-year female presented to our clinic in May 2019 with persistent sero-purulent discharge from sinus over abdominal skin. She was of generally good health, with no fever, weight loss, good appetite and bowel function. Her body mass index was also normal. The patient had previously undergone a cesarean section in April 2018 for premature rupture of membranes and non-progress of labour. The surgery and puerperal period were uneventful and the patient was discharged on 8th post-operative day after her interrupted skin sutures were cut. The patient presented with document high-grade fever in June 2018 to a private clinic. She was thoroughly investigated and evaluated, although the focus of infection was unknown, she was started on antipyretics and antibiotics. In August 2018, a localized painful swelling was noted by the patient herself over the abdomen, at the level of the umbilicus and right mid-clavicular line. It was $5 \times 5 \mathrm{~cm}$ red and warm to touch. Ultrasound was done in a private clinic nearby patient's residence, followed by incision and drainage of the abscess. Despite the regular aseptic dressings and antibiotics, the abscess continued to drain on and off. In May 2019 in our hospital patient underwent an ultrasound and contrast-enhanced computed tomography, which suggested $6.3 \times 3.9 \times 3 \mathrm{~cm}$ collection in the right adnexal region abutting the right lateral wall of the uterus and a fistulous tract communicating with abdominal skin. When she had come to us, the fistula had spontaneously sealed off with a scab. For the same she underwent surgery, wide local excision of the fistulous tract around elliptical skin incision was done. The track was found to be reaching the abdominal cavity into the adherent omentum with no extension to any pelvic organs. On histopathological examination of this $6 \mathrm{~cm}$ long fistulous tract, there was 
evidence of chronic inflammation. Zeil-Neelsen (ZN) staining and cartridge based nucleic acid amplification test (CBNAAT) were negative. The patient was asymptomatic in the post-operative period and on regular follow up for the next 3 months.

\section{DISCUSSION}

The development of delayed peritoneo-cutaneous fistula has not been previously reported post-cesarean section but has been seen as a complication of difficult cholecystectomy, nephrectomy, peritoneal dialysis and secondary to perforated Dalkon shield. ${ }^{3-6}$

Post cesarean section complications, both early and late are known since times. Even in a study dating back to 1983, the overall complication rate was $14.5 \%$ and the most common complication was infection (13.3\%), in particular, endometritis $(6.6 \%)$, urinary tract infection $(3.1 \%)$, and wound infection (1.6\%). A lower complication rate was seen in elective operations $(4.7 \%)$ compared with emergency operations $(24.2 \%)$ and four significant factors that predisposed to postoperative morbidity were identified: duration of ruptured membranes before the operation, duration of labour before the operation, anaemia, and obesity. ${ }^{7}$ In another study, febrile morbidity and infection complications were $16.2 \%$ and $12.4 \%$ of subjects, respectively. Eighty-five subjects had 95 surgical site infections $(9.8 \%)$, and several risk factors were independently associated with infection. ${ }^{8}$ Our patient had a prolonged duration of ruptured membranes and labour before her emergency cesarean section. This leading to infection with localized blood collection may have led to the abscess formation followed by delayed healing and then fistula.

Management of fistulae such as the peritoneo-cutaneous fistula in our case includes diagnosis via computed tomography or magnetic resonance cross-sectional imaging and sinogram, to identify the length and course of the tract, its extent and termination; and identify any associated anatomical disturbances. When associated with an intra-abdominal abscess, local exploration and drainage may be worthwhile, but definitive treatment is by complete tract excision. Needless to say, prophylaxis remains the forefront with a final thorough inspection before closure.

\section{CONCLUSION}

In our patient, the development of wound hematoma may have occurred in the post-operative period after cesarean section, which may have led to localized wound breakdown, delayed healing and fistula formation.

Funding: No funding sources

Conflict of interest: None declared

Ethical approval: Not required

\section{REFERENCES}

1. Kumar TS, Saklani AP, Vinayagam R, Blackett RL. Spilled gall stones during laparoscopic cholecystectomy: a review of the literature. Postgrad Med J. 2004;80(940):77-9.

2. Castellón-Pavón CJ, Morales-Artero S, MartínezPozuelo A, Valderrábano-González S. Complications due to spilled gallstones and surgical clips left in the abdomen during laparoscopic cholecystectomy. Cir Esp. 2008;84(1):3-9.

3. Kumar S. Peritoneo-cutaneous fistula from spilled gall bladder calculus following laparoscopic cholecystectomy. Clin Case Rep. 2017;5(5):720-2.

4. Bissada NK, Redman JF, Barbour GL. Delayed Peritoneal-Cutaneous Fistula; a Complication of Bilateral Nephrectomy. Br J Urol. 1975;47(3):262.

5. Ram R, Desai M, Swarnalata G, Dakshinamurty KV. Peritoneo-cutaneous Fistula: An Unusual" complication" of Continuous Ambulatory Peritoneal Dialysis. Indian Journal of Peritoneal dialysis. 2009;16(1):35-6.

6. Slaughter L, Morris DJ. Peritoneal-cutaneous fistula secondary to a perforated Dalkon shield. Am J Obstet Gynecol. 1976;124(2):206-7.

7. Nielsen TF, Hökegård KH. Postoperative cesarean section morbidity: A prospective study. American J Obstetr Gynecol. 1983;146(8):911-6.

8. Tran TS, Jamulitrat S, Chongsuvivatwong V, Geater A. Risk Factors for Postcesarean Surgical Site Infection. 2000;95(3):5.

Cite this article as: Rana A, Mohindroo N. A rare case of peritoneo-cutaneous fistula after cesarean section. Int J Reprod Contracept Obstet Gynecol 2020;9:4299-300. 